\title{
Structural study of the inclusion compounds of thymol, carvacrol and eugenol in $\beta$ cyclodextrin by X-ray crystallography
}

\author{
Kostas Bethanis*, Pavlos Tzamalis, Frantzeska Tsorteki, Areti Kokkinou, Elias \\ Christoforides and Dimitris Mentzafos \\ Agricultural University of Athens, Physics Laboratory, Iera Odos 75, 11855 \\ Athens, Greece \\ Phone: ++30 2105294211 \\ Fax: ++30 2105294233 \\ Email: kbeth@aua.gr \\ URL : http://www.aua.gr/ bethanis/en
}

\section{Abstract}

The crystal structures of the inclusion compounds of thymol, carvacrol and eugenol, (components of essential oils of vegetable origin) in $\beta$-cyclodextrin have been determined. Thymol $/ \beta$-CD crystallizes in the space group P1 containing two host molecules in its asymmetric unit whereas both carvacrol $/ \beta$-CD and eugenol $/ \beta$-CD complexes crystallize in the space group $\mathrm{C} 2$. In all three complexes two host molecules form head-to-head dimers their guest/host stoichiometry being: 1/2 (carvacrol $/ \beta$-CD), $2 / 2$ (thymol $/ \beta$-CD) and $3 / 2$ (eugenol $/ \beta$-CD). In the cases of the thymol $\beta$-CD and the carvacrol $/ \beta$-CD complexes the $\beta$-CD dimers are arranged according to the channel packing mode. The accommodation of the geometrical isomer guests is performed solely by their hydrophobic groups revealing the leading role of the hydrophobic driving forces in the complexation process whereas the position of their hydroxyl group affects the stoichiometry of the formed dimeric complexes. In the case of the eugenol/ $\beta$-CD dimeric complex one guest molecule is found lying between the $\beta$-CD groups in a sandwich fashion whereas the other two symmetry related guests protrude outwards the narrower rim of the hosts with only their hydrophobic allylchain located inside the hosts' cavities. This arrangement prohibits the formation of a channel and the observed crystal packing is that of a Tetrad mode.

Keywords: thymol; carvacrol; eugenol; $\beta$-cyclodextrin; inclusion complexes; $X$ ray crystallography

Abbreviations: $\beta$-Cyclodextrin, $\beta$-CD 


\section{Introduction}

Thymol (5-methyl-2-isopropylphenol), carvacrol (5-isopropyl-2-methylphenol) and eugenol [2-methoxy-4-(2-propenyl) phenol] (Scheme 1) are present in the essential oils from herbs and spices, such as thyme (Thymus vulgaris), oreganum (Origanumsyriacum), and clove (Caryophilliflos) [1*]. These three compounds have been shown to have bactericidal, microbicidal, and fungicidal properties, therefore they have been used as antiseptic, antispasmodic, tonic, and carminative in pharmaceutical industry [2*]. They have also attracted great attention in food industry as natural preservatives [3, 4*]. However, their use has been limited, because of their sublimation, sensitivity to light decomposition and low watersolubility [ $\left.5^{*}\right]$. One way to stabilize and use these substances is by inclusion in suitable host molecules. Cyclodextrins (CDs) are frequently used as host molecules accommodating such guest molecules modifying beneficially their physicochemical properties such as: stabilization of light- or oxygen-sensitive substances, fixation of very volatile substances and a marked increase of water solubility [6*]. CDs are a family of cyclic oligosaccharides that are composed of $\alpha$-(1,4)-linked glucopyranose subunits. As a result of their molecular structure and shape, they possess a unique ability to act as molecular containers (molecular capsules) by entrapping guest molecules in their apolar, hydrophophic, internal cavity.

The guest molecules are held inside the CD cavity by non-covalent interactions, such as hydrogen bonds, van der Waals or hydrophobic interactions, and the host:guest system is in a dynamic equilibrium. Therefore, encapsulation in CDs offers additionally a slow release of the guests sustaining their action. The use of natural and modified CDs has been well established in cosmetic, pharmaceutical and industrial formulations, including food industry. The low cost, biocompatible and effective degradation makes $\beta$-CDs the most used molecular encapsulants [7*]. The inclusion compounds of thymol, carvacrol and eugenol in $\beta$-CD have been formed aiming to optimize and increase the potential fields of applications of these substances and they have been studied by several methods [8-13*]. Recently the determination of a crystal structure of the complex of thymol with $\beta$-CD was reported [14*]. X-ray crystallography provides the most accurate and absolute structural information of the complex in the crystalline state. We report here the 
crystal structures of the inclusion compounds of thymol, carvacrol and eugenol encapsulated in $\beta$-CD (assigned as thymol $/ \beta-\mathrm{CD}$, carvacrol $/ \beta$-CD and eugenol $/ \beta$ CD respectively).

\section{Experimental}

\subsection{Sample preparation}

Carvacrol and thymol were isolated from the essential oils extracted from Lamiaceae Species [15*] and kindly offered to us by the chemistry laboratory of the Agricultural University of Athens. Eugenol and $\beta$-CD were purchased from Sigma-Aldrich and Fluka respectively.

Several crystallization attempts by dissolving different host:guest molar ratios (1:1,1:1.5 and 1:2) were made for each of the three different guests. Crystals of the best form and quality were obtained from aqueous solutions of 1:1, 1:1.5 and 1:1.5 host:guest molar ratios for the $\beta$-CD inclusion compounds with thymol, carvacrol and eugenol respectively. In particular, $59 \mathrm{mg}$ of $\beta$-CD (0.052 mmoles) was weighted into a crimp top vial (Witeg) and $2 \mathrm{~mL}$ of distilled water was added. For the preparation of the thymol $/ \beta$-CD complex an equimolar quantity $(7.8 \mathrm{mg}$, 0.052 mmoles) of thymol was added and the vial was sealed. For the preparation of the carvacrol $/ \beta$-CD and the eugenol $/ \beta$-CD complexes, the vials containing the saturated $\beta$-CD solution were sealed and then $0.012 \mathrm{~mL}(0.078$ mmoles $)$ of carvacrol (molar ratio of host:guest equals to $1: 1.5)$ and $0.012 \mathrm{~mL}(0.078 \mathrm{mmoles})$ of eugenol (molar ratio of host:guest equals to 1:1.5), were injected into the sealed crimp top vials. The mixtures were stirred for about $1 \mathrm{~h}$ at $343 \mathrm{~K}$ until they were limpid. Then they were gradually cooled to room temperature over a seven-day period in order to produce crystals suitable for X-ray data collection.

\subsection{X-ray data collection}

High resolution X-ray data from crystals of all three complexes were collected using the synchrotron-radiation light source at the EMBL X11 beamline at the DORIS storage ring, DESY, Hamburg and a marCCD 165 detector. Eugenol/ $\beta$ $\mathrm{CD}$ and thymol $/ \beta$-CD crystal data were collected at cryogenic temperature. The crystals of the complexes kept under paraffin oil, were picked with a cryoloop and flash cooled under the nitrogen stream to $100 \mathrm{~K}$. The carvacrol $/ \beta$-CD diffraction 
data were collected at room temperature $(293 \mathrm{~K})$ as the cryoprotectant oil was damaging the crystal. The processing and scaling of the data sets has been performed by using the programs DENZO and SCALEPACK [16*].

\subsection{Structure solution and Refinement}

The carvacrol/ $\beta$-CD complex was solved by the isomorphous replacement method using the coordinates of the macrocycle of the indole-butyric-acid/ $\beta$-CD complex $\left[17^{*}\right]$. The eugenol $/ \beta$-CD and thymol $/ \beta$-CD complexes were solved by a Patterson vector search method and Fourier recycling with the program DIRDIF99 [18*] using the coordinates of the macrocycle of the indole-butyric-acid/ $\beta$-CD complex in the case of the eugenol $/ \beta$-CD and the coordinates of the macrocycle of the 3,5dimethylbenzoic acid/ $\beta$-CD complex [19*] in the case of the thymol/ $\beta$-CD. All the atomic positions of the host, guest and the water molecules were located and refined by sequential difference electron density maps $(\Delta \rho)$, using the Shelxl program [20*], on a $F^{2}$ basis. Shelxl used under the interface and the graphical display support of the Shelxle program [21*]. The geometrical analysis and the validation of the crystal structures have been carried with the programs Platon [22*] and Olex2 [23*]. In all three data sets of the complexes the number of the observed reflections was sufficient for the introduction of anisotropic thermal parameters only for the oxygen atoms of the host molecules which have not been found disordered over two or three sites. Hydrogen atom positions linked to primary, secondary or tertiary carbon atoms of the host molecules were placed in calculated positions and their thermal parameters were set to $1.2 \mathrm{U}_{\text {iso }}$ of the isotropic thermal parameter of the corresponding carbon atom. Finally, by applying extinction correction, zero weight was given during the final refinement cycles to 3, 42 and 8 reflections exhibiting poor agreement in the cases of carvacrol $/ \beta$-CD, eugenol $/ \beta$ - $\mathrm{CD}$ and thymol $/ \beta$-CD respectively. The final lattice parameters along with all the data collection parameters of the complexes are quoted in Table 1. 


\section{Results and discussion}

\subsection{Thymol/ $\beta$-CD}

\subsubsection{Description of the structure}

The thymol/ $\beta$-CD inclusion complex crystallizes in the space group P1 with unit cell dimensions $a=15.289(15) \AA, b=15.443(15) \AA, c=15.549(16) \AA, \alpha=$ $104.432(5)^{\circ}, \beta=101.076(5)^{\circ}$ and $\gamma=104.036(5)^{\circ}$. In the asymmetric unit two $\beta$ CD host molecules, host(A) and host(B), form a head-to-head dimer via the O3nA ... O3(8-n)B hydrogen bonds where O3nA denotes the secondary 3-hydroxyls of the $n^{\text {th }}$ glucose unit of the host(A) and O3(8-n)B the facing 3-hydroxyls of the (8$n)^{\text {th }}$ glucose unit of the host(B) (D...A distances range from 2.712(7) to 2.842(7) $\AA$; $C$-D...A angles range from $111.66(16)$ to $\left.121.02(7)^{\circ}\right)$. Inside the formed dimeric cavity two thymol guest molecules $\mathrm{G}(\mathrm{A})$ and $\mathrm{G}(\mathrm{B})$ are accommodated and therefore the guest/host stoichiometry of the complex is $2 / 2$. The unit cell contains also 16 water molecules distributed over 27 sites. The guest molecule G(A) is located inside the hydrophobic cavity of the host $(\mathrm{A})$ and is found disordered over three sites: G(A1), G(A2) and G(A3), with occupancies $0.45,0.30$ and 0.25 respectively. The other guest molecule, $G(B)$, lies inside the hydrophobic cavity of the host(B) and is disordered over two sites: $G(B 1)$ and $G(B 2)$ with occupancies 0.70 and 0.30 respectively. The geometrical constraints of the positions of the occupied sites indicate that the co-existent encapsulated G(A) and G(B) molecules are located at the following three possible pairs of sites: G(A1) G(B1) with occupancy $0.45, \mathrm{G}(\mathrm{A} 2)$ - G(B2) with occupancy 0.30 and G(A3) G(B1) with occupancy 0.25 .

In all occupied sites the thymol molecules are oriented with their methyl group pointing towards the secondary hydroxyls rim and their isopropyl group located at the primary hydroxyls rim. The depth of immersion of the encapsulated molecules is such that their methyl groups are found at the intercavity region formed by the $\beta$-CD dimer whereas their isopropyl groups lay inside the hydrophobic cavity of each host molecule. The phenyl groups of the G(A1), G(A2) and G(A3) and those of the $\mathrm{G}(\mathrm{B} 1)$ and $\mathrm{G}(\mathrm{B} 2)$ form angles varying between $67.5(5)$ and $72.6(5)^{\circ}$ with the mean plane of the glucosidic $\mathrm{O} 4 n \mathrm{~A}$ atoms of the corresponding host(A) and 
host(B) molecule respectively. As it can been seen from the Figures (1a) and (1b) the inclination of the planes of the aromatic rings of the pair $\mathrm{G}(\mathrm{A} 2)-\mathrm{G}(\mathrm{B} 2)$ is the opposite compared to that of the pairs $G(A 1)-G(B 1)$ or $G(A 3)-G(B 1)$. On the other hand, the main difference between the pairs $\mathrm{G}(\mathrm{A} 1)-\mathrm{G}(\mathrm{B} 1)$ and $\mathrm{G}(\mathrm{A} 3)-\mathrm{G}(\mathrm{B} 1)$ is detected at the orientation of the $-\mathrm{OH}$ group of the accommodated $\mathrm{G}(\mathrm{A})$ molecule occupying the G(A1) or the G(A3) site inside the host(A) cavity. The hydroxyl group of the guest molecules occupying all five sites forms a hydrogen bond as a proton donor with the $\mathrm{i}_{\text {th }}$ etheric cyclodextrin atom, O4(i). In addition, the oxygen atom of the same $-\mathrm{OH}$ guest's group donates its electron pairs to form two $\mathrm{CH}$... O bonds with the $\mathrm{H} 5(\mathrm{i})$ and $\mathrm{H} 5(\mathrm{i}+1)$ atoms linked to the tertiary $\mathrm{C} 5(\mathrm{i})$ and C5(i+1) atoms of the $i_{\text {th }}$ and the $i_{\text {th }}+1$ D-glucopyranoside units bridged at the O4(i) by the $(1,4)$ glucoside bond (Fig. 2a). The geometrical features justifying the existence of the above mentioned H-bonds are given in Table 2.The measured distances and angles meet the criteria for the formation of linear $\mathrm{CH} \ldots \mathrm{O}$ bonds [24*]. In addition, the $\pi$-plane of the guest's phenyl ring is oriented inside the $\beta$-CD hydrophobic cavity in a way favoring the formation of $\mathrm{CH} / \pi$ interactions with the $\mathrm{C} 3-\mathrm{H} 3$ of the host. In Table 2 some geometrical features are listed following the Takahashi et al $\left[25^{*}\right]$ method of surveying and classifying the $\mathrm{CH} / \pi$ contacts (see Figure 1 in Takahashi et al, 1990). Moreover, the face-to-face arrangement of the two guest molecules inside the dimeric cavity, observed in all the three possible pairs of occupied sites, indicates the formation of mutual $\mathrm{CH} / \pi$ interactions between the methyl group of the one guest and the $\pi$-system of the phenyl ring of the other (Fig. 2b). Some indicative geometrical features of these interactions are given in Table 3. In order to obtain these measurements, $\mathrm{H}$-atoms linked to the carbon atoms of the thymol, except the highly disordered isopropyl group, were placed in calculated positions and included in the refinement using the riding model. Finally, weak van der Waals interactions also contribute to the stabilization of the guest molecules at the observed occupied sites inside the hydrophobic $\beta$-CD cavity.

\subsubsection{The molecular packing}

The thymol $/ \beta$-CD complex crystallises as a dimer in the space group $P 1$, its cell dimensions are slightly greater than $15 \AA$ and the observed crystal packing mode is that of a Channel $(\mathrm{CH})$ (Fig. 3). This is in agreement with the classification of 
the crystal packing modes of the $\beta$-CD dimeric complexes according to their space group and cell dimensions [26*]. The channels are formed by dimers stacked along the $c$ axis. The shifting between the dimers of the channel is 3.02(6) $\AA$. The dimeric complexes of the same channel are connected via (i) H-bonds between the two facing primary hydroxyls O64A ... O64B $(\mathrm{d}=2.765(6) \AA)$ and O66A ... O62B $(\mathrm{d}=2.758(8) \AA)$ of the successive dimers, (ii) various $\mathrm{CH} \ldots \mathrm{O}$ bonds between the rest primary hydroxyls and the facing C6-atoms of the successive dimers, and (iii) H-bonds formed between the primary hydroxyls and the water molecules of the crystal. Moreover, the adjacent channels are connected via (i) H-bonds between the primary hydroxyls O63B ... O67B (d=2.760(2) $\AA$ ) and the secondary hydroxyls O25A ... O27B (d=2.738(6) $\AA$ ) of the adjacent complexes, (ii) various $\mathrm{CH}$... O interactions and (iii) the water net of the crystal.

\subsection{Carvacrol/ $\beta-C D$ complex}

\subsubsection{Description of the structure}

The carvacrol/ $\beta$-CD inclusion complex crystallizes in the space group $\mathrm{C} 2$ with unit cell dimensions $a=19.300(19) \AA, b=24.588(2) \AA, c=15.844(3) \AA$, and $\beta=$ $109.491(5)^{\circ}$. The asymmetric unit contains one $\beta$-CD molecule, one carvacrol molecule having an occupancy of 0.50 , the guest/host stoichiometry being therefore $1 / 2$, and 8 water molecules distributed over 20 sites. Two complexes related by the 2-fold symmetry $b$-axis form a dimer via the O3n ... O3'(8-n) hydrogen bonds (D...A distances range from 2.756(10) $\AA$ to 2.870(14) $\AA$; C$D$... A angles range from $116.1(6)^{\circ}$ to $\left.118.9(6)^{\circ}\right)$.

The carvacrol guest molecule is found fully immersed inside the host's hydrophobic cavity (the distance between the carvacrol's phenyl centroid and the host's O4n mean plane is $1.355(9) \AA$ ) forming an angle of $68.0(5)^{\circ}$ with the mean plane of the glucosidic $\mathrm{O} 4 \mathrm{n}$ atoms. The hydroxyl group of the carvacrol is located at the broader rim (secondary hydroxyls) and the isopropyl group at the narrower rim (primary hydroxyls) of the host (Fig. 4). However, the hydroxyl group of the guest is located at a position which forbids the existence of a second carvacrol molecule within the formed dimeric cavity. Indeed, as mentioned above, the guest molecule in the asymmetric unit has half occupancy and thus only one carvacrol molecule can be accommodated inside the formed by the crystallographic 
symmetry dimeric cavity, as otherwise, the distance between the oxygen atoms of the two guests linked by the 2-fold symmetry b-axis would be about $1.0 \AA$.

The inclination of the guest molecule is justified by the $\mathrm{CH} / \pi$ interactions between the $\mathrm{H}$-atoms linked to the $\mathrm{C} 3$-atoms of the host and the $\pi$-system of the guest's phenyl. In particular, by using the calculated positions of the $\mathrm{H}$-atoms linked to the host's C-atoms the following interactions are observed at the region 2 of the guest's $\pi$-system according to the Takahashi et al [25*] method of surveying the $\mathrm{CH} / \pi$ contacts: $\mathrm{C} 32-\mathrm{H} 32 \ldots \pi\left(\mathrm{C}^{1}: \mathrm{C} 5 \mathrm{~A}, \mathrm{D}_{\mathrm{atm}}=2.806(2), \theta=19.2(5)^{\circ}\right.$, $\left.\omega=106.6(17)^{\circ}\right)$ and $\mathrm{C} 31-\mathrm{H} 31 \ldots \pi\left(\mathrm{C}^{1}: \mathrm{C} 1 \mathrm{~A}, \mathrm{D}_{\mathrm{atm}}=2.77(6), \theta=8.7(9)^{\circ}\right.$, $\left.\omega=105.9(7)^{\circ}\right)$. Contrary to the case of the thymol/ $\beta$-CD complex, no H-bond is formed between the hydroxyl group of the encapsulated carvacrol molecule and the host. The lack of these $\mathrm{H}$-bonds is due to the position of the $-\mathrm{OH}$ of the guest which in the case of the carvacrol is located outside the host's secondary hydroxyls rim (at a distance of 0.70(7) $\AA$ above the mean plane of the O2n and O3n host's oxygens) whereas in the case of the thymol guest its $-\mathrm{OH}$ is laid at the region of the host's O4 atoms (at a distance of about $0.2 \AA$ from the host's O4n mean plane).

\subsubsection{The molecular packing}

The carvacrol/ $\beta$-CD complex dimers stack according to the channel $(\mathrm{CH})$ packing mode [26*] along the $c$ axis. The mean plane of the glucosidic $\mathrm{O} 4 \mathrm{n}$ atoms forms an angle of about $9^{\circ}$ with the $a b$ plane and the displacement of two successive dimers in the channel is about $2.7 \AA$ (Fig. $5 \mathrm{a}$ and b). The dimeric complexes of the same channel are connected via (i) H-bonds between the facing primary hydroxyls of the successive dimers: O64A ... O64A (A disordered position of O64) at $\mathrm{d}=2.90(6) \AA \AA$ or O64A ... O64B (B disordered position of O64) at $\mathrm{d}=2.99(5) \AA$; and O61A ... O66B at d=2.86(5) $\AA$, (ii) various $\mathrm{CH}$... O bonds between the rest primary hydroxyls and the facing C6-atoms of the successive dimers, and (iii) H-bonds formed between the primary hydroxyls and the water molecules of the crystal. The adjacent channels are connected via (i) $\mathrm{H}$-bonds between the primary hydroxyls $\mathrm{O} 63$... O61 (the distances between the $\mathrm{O} 61$ and the A, B and C occupied sites of O63 being 2.85(2) $\AA, 2.83(4) \AA$ and 2.91(3) $\AA$ respectively) and the secondary hydroxyls O25 ... O27 (d=2.79(1) A) of the 
adjacent complexes, (ii) various $\mathrm{CH} \ldots \mathrm{O}$ interactions and (iii) the water net of the crystal.

\subsection{Eugenol/ $\beta$-CD complex}

\subsubsection{Description of the structure}

The eugenol $/ \beta$-CD inclusion complex crystallizes in the space group $\mathrm{C} 2$ with unit cell dimensions $a=19.589(5) \AA, b=24.203(3) \AA, c=16.378(19) \AA$, and $\beta=$ $103.484(19)^{\circ}$. The asymmetric unit contains one $\beta$-CD molecule, two guest molecules (molA and molB having occupancy factors of 1.0 and 0.5 respectively) and 12.5 water molecules distributed over 24 sites (Fig. 6). Two complexes related by the 2-fold symmetry b-axis form a dimer via the $\mathrm{O} 3 \mathrm{n} \ldots \mathrm{O}^{\prime}(8-\mathrm{n})$ hydrogen bonds $(D \ldots A$ distances range from $2.767(5) \AA$ to $2.908(6) \AA ̊$ except for the $\mathrm{O} 34$... O3'4 pair where a distance of 3.186(8) $\AA$ is observed due to the formation of H-bonds between these hosts' secondary hydroxyls and the hydroxyl of the guest molecule (molB) encapsulated inside the dimeric cavity; C-D...A angles range from $114.0(3)^{\circ}$ to $\left.118.5(3)^{\circ}\right)$. Therefore, the guest/host stoichiometry of the dimer is $3 / 2$.

MolA has been found located at the region of the narrower rim of the host, its main part being outside the host's cavity and only its hydrophobic allyl chain entering in it. Its oxygen atoms, located at the interdimeric space, are hydrogen bonded to the water molecules of the water net. In particular, its etheric oxygen atom, $\mathrm{O} 2 \mathrm{~A}$, is $\mathrm{H}$-bonded to the water molecule named OW9 (O2A...OW9A, OW9B d= 2.991(11), 2.99(4) $\AA$ and C2A-O2A...OW9A angle $\left.=127.4(6)^{\circ}\right)$ and its hydroxyl oxygen atom, $\mathrm{O} 1 \mathrm{~A}$, is found $\mathrm{H}$-bonded to the water molecule named OW6 (O1A...OW6 d = 2.669(8) $\AA$ and C1A-O1A...OW6 angle $\left.=116.9(5)^{\circ}\right)$. The plane of its phenyl ring forms an angle of $68.6(2)^{\circ}$ with the mean plane of the glucosidic $\mathrm{O} 4 n$ atoms and its $\pi$-system is connected via a $\mathrm{CH} / \pi$ interaction with the $\mathrm{H}$-atom linked to the $\mathrm{C} 6$-atom of the $\beta$-CD of the adjacent dimer (C62-H62 ... $\pi, D_{\operatorname{pln}}=2.413(4) \AA, \theta=8.5(3)^{\circ}$, thus $\mathrm{CH} / \pi$ interaction observed at the region 1 of the guest's phenyl $\pi$-system according to the Takahashi et al $\left[25^{*}\right]$ method). Moreover, its methyl group is connected via an $\mathrm{CH}$... O interaction (CA ... O64 
$\mathrm{d}=3.084(15) \AA$ ) with the $\mathrm{O} 64$ atom of the $\beta$-CD of the dimer which lays aside to the one connected to the molA with the aforementioned $\mathrm{CH} / \pi$ interaction. The observed mode of complexation of the molA with the $\beta$-CD leaves the guaiacol of the guest outside the hydrophobic cavity and thus there is enough space within the formed $\beta$-CD dimer to host one more guest molecule, molB. MolB is accommodated at the dimeric interface in a sandwich fashion and it is disordered over two sites with occupancy factors of 0.5 each (Fig. 6). Its phenyl ring is about parallel to the $\mathrm{O} 4 n$ mean plane of the host forming an angle of $3.6(4)^{\circ}$ with it. Its hydroxyl group forms a hydrogen bond with the $\mathrm{O} 34$ of the secondary hydroxyl of the guest (O1B ...O34 d = 2.730(14) $\AA$ and C1BO1B...O34 angle $\left.=127.4(9)^{\circ}\right)$. As a result of the formation of this $\mathrm{H}$-bond, the O3n ... O3'(8-n) H-bonds net, which forms the dimer, is disrupted at the pair of the $\mathrm{O} 34 \ldots \mathrm{O}^{\prime} 4(\mathrm{~d}=3.186(8) \AA)$ as mentioned above. In addition, a $\mathrm{CH} / \pi$ interaction, at the region 2 of the $\pi$-plane of the guest's phenyl ring (according to the Takahashi et al [25*] method), with the H36-atom linked to the host's C36atom and some van der Waals interactions between the guest and the host atoms are observed.

\subsubsection{The molecular packing}

The dimers are stacked along the $c$ axis (Fig. 7a), their approximate seven-fold molecular axis forms an angle of about $13^{\circ}$ with it and the mean plane of the $\mathrm{O} 4 n$ glucosidic atoms forms an angle of about $11^{\circ}$ with the $a b$ plane. The molecular packing usually observed in the $\beta$-CD dimeric complexes in the space group $\mathrm{C} 2$ is that of a Channel $(\mathrm{CH})\left[26^{*}\right]$. However, in the case of the eugenol/ $\beta$-CD dimeric complex crystallizing also in the space group $\mathrm{C} 2$, the unit cell dimensions are noticeably different from those adopting the $\mathrm{CH}$ packing mode. For example, by comparing the eugenol $/ \beta$-CD unit cell to that of the carvacrol $/ \beta$-CD presented in this work (Table 1) we can see that the dimension of the $c$ axis is about $1 \AA$ greater and the angle $\beta$ about $6^{\circ}$ smaller. As a consequence, eugenol $/ \beta$-CD is not isomorphous to any of the other $\beta$-CD dimeric complexes crystallizing in the $\mathrm{C} 2$ space group and the crystal packing is not the usual $\mathrm{CH}$ but it seems to be the less frequently observed Tetrad Mode (TT) [27*, 28*] (Fig. 7b). The shifting of the 
dimers of the same stack may be attributed to the position of the molA accommodated outside the host cavity that prohibits the formation of a channel.

\subsection{Conformation of the host molecules}

The host molecules of all the three studied complexes have a similar conformation. The only differences among them are detected in the conformation of their primary hydroxyl groups. In the case of the carvacrol/ $\beta$-CD complex all the primary hydroxyl groups except one are disordered over two, three or four sites. Three of them exhibit the gauche-trans conformation $(g t)$ whereas all the rest have the gauche-gauche ( $g g$ ) conformation. In the case of the eugenol/ $\beta-\mathrm{CD}$, two primary hydroxyls have the $g t$ conformation and the rest primary hydroxyls (two of them are disordered over two sites) have the $g g$ conformation.

Finally, in the case of the thymol $/ \beta$-CD, one primary hydroxyl of host(A) has been found disordered over two sites adopting both $g g$ and $g t$ conformation. All the rest primary hydroxyls of host(A) are not disordered, five of them have the $g g$ and one the $g t$ conformation. Two primary hydroxyls of host(B) have been found disordered over two sites each. The one adopts exclusively the $g t$ conformation whereas the other the $g g$ conformation. All the rest non-disordered primary hydroxyls of host(B) have the $g g$ conformation.

\section{Concluding remarks}

Both carvacrol $/ \beta$-CD and eugenol $/ \beta$-CD crystallize in the space group $C 2$ whereas thymol $/ \beta$-CD has been found to crystallize in the space group $P 1$ containing two host molecules (host(A) and host(B)) in its asymmetric unit. In all three complexes two host molecules form head-to-head dimers, via the $\mathrm{O} 3 n \ldots \mathrm{O} 3(8-n)$ hydrogen bonds. In carvacrol $/ \beta$-CD and eugenol $/ \beta$-CD the dimers are formed by two host molecules related by a two-fold axis, whereas in thymol/ $\beta$-CD the crystallographic symmetry independent host(A) and host(B) form the dimer. In a recent publication $\left[14^{*}\right]$ the thymol/ $\beta$-CD inclusion complex has been found to crystallize in the space group $\mathrm{C} 2$ with cell dimensions close to those of the carvacrol/ $\beta$-CD crystal structure reported here. The crystal packing of the thymol/ $\beta$-CD reported by Fan et al. [14*] is that of a Channel formed by head-tohead dimers containing two guest molecules (one in each $\beta$-CD cavity). This 
molecular packing is the same to the one determined for both thymol/ $\beta$-CD and carvacrol/ $\beta$-CD crystal structures in the present work. By observing the asymmetric unit of our thymol $/ \beta$-CD crystal structure illustrated in Figs 1 a and $1 \mathrm{~b}$, the two pairs $\mathrm{G}(\mathrm{A} 1)-\mathrm{G}(\mathrm{B} 1)$ and $\mathrm{G}(\mathrm{A} 2)-\mathrm{G}(\mathrm{B} 2)$ seem to be symmetry related whereas the existence of the $3^{\text {rd }}$ pair, $G(A 3)-G(B 1)$, in particular, the opposite orientation of the hydroxyl group of the guest occupying the G(A3) site, breaks the crystallographic symmetry and reduces the unit cell to the triclinic P1. Symmetry may also break because of the slightly different immersion depth observed between the $\mathrm{G}(\mathrm{A})$ and the $\mathrm{G}(\mathrm{B})$ guest molecules. Although the inclination of the phenyl group relative to the $\mathrm{O} 4$ mean planes is about the same, the $G(B)$ sites are shifted towards the dimeric cavity compared to the $G(A)$ sites as shown by the measured distances between the centroids of the phenyl groups and the $\mathrm{O} 4$ mean plane of the corresponding host molecules (distance varies between $0.979(3)-1.228(3) \AA$ for the sites occupied by the G(A) guest and 1.366(2) 1.420 (2) $\AA$ for the sites occupied by the G(B) guest).

By comparing the $\beta$-CD inclusion complexes of the two geometrical isomers, carvacrol and thymol, we see that both crystallize forming Channels of $\beta$-CD dimers but their guest/host stoichiometry differs being $1 / 2$ and $2 / 2$ respectively. In the case of the carvacrol $/ \beta-\mathrm{CD}$, where only one guest molecule is found encapsulated inside the formed $\beta$-CD dimer, the depth of immersion and the inclination of the guest molecule are close to those observed in the case of the thymol/ $\beta$-CD complex (Fig. 8). This indicates that in both cases the location of the accommodation of the guest molecule inside the hydrophobic $\beta$-CD cavity is coordinated by the hydrophobic phenyl and isopropyl groups and not by the position of the hydroxyl group giving once more a strong evidence of the leading role of the hydrophobic driving forces in the complexation process. On the other hand, the position of the hydroxyl group, at the given immersion depth of the guest inside the host's hydrophobic cavity, in the case of the thymol/ $\beta$-CD permits the formation of H-bonds with the host's etheric oxygen atoms whereas in the case of the carvacrol $/ \beta$-CD complex forbids sterically the existence of a second carvacrol molecule within the formed dimeric cavity. This leads to the reduced $1 / 2$ guest/host stoichiometry observed for the carvacrol/ $\beta$-CD complex. Moreover, the guest molecules in both thymol/ $\beta$-CD and carvacrol $/ \beta-\mathrm{CD}$ complexes are 
found oriented with their isopropyl group located at the narrower rim (primary hydroxyls) of the host. This orientation, observed in our study of the complexes in the crystalline state, is opposite to the orientation predicted by NMR studies of the inclusion complexes in aqueous solution $[8,9 *]$.

The formation of the $\beta$-CD dimers in all the three complexes and the $1 / 2$ and $3 / 2$ guest/host stoichiometry of the carvacrol/ $\beta$-CD and the eugenol/ $\beta$-CD complexes observed by the crystal structure determination in the present work has not been observed in the characterization of the complexes with NMR experiments performed in aqueous solution where for all the three complexes monomers of $1 / 1$ stoichiometry have been reported $\left[8,9^{*}\right]$. Moreover, the present study of the eugenol $/ \beta$-CD complex in the crystalline state reveals a complete different mode of complexation and orientation of the guest molecules compared to the previous NMR and molecular modeling structural studies of the complex in aqueous solution. The geometry of the complex in aqueous solution which has been established from the NMR data is such that the phenyl ring of the eugenol enters into the $\beta$-CD cavity from the wider rim and the guest molecule is arranged inside the $\beta$-CD cavity with the allyl group folded towards the phenyl ring $9,10^{*}$. Moreover, fluorescence and infrared spectroscopy studies have proposed a 1/1 guest/host complex in solid state with a eugenol molecule included partially into the cavity of the $\beta$-CD [29*]. Molecular modeling studies confirming spectroscopy and thermal analysis studies also proposed a 1/1 complex with the eugenol guest molecule having the opposite orientation that the one observed in this work and with its phenyl ring about parallel to the seven-fold axis of the $\beta$ $\mathrm{CD}\left[13^{*}\right]$.

\section{Supplementary data}

CCDC 850749 - 850751 contains the supplementary crystallographic data for this paper. These data can be obtained free of charge from The Cambridge Crystallographic Data Centre via www.ccdc.cam.ac.uk/data_request/cif. 


\section{Acknowledgements}

We thank the European Community, Research Infrastructure Action under the FP6 "Structuring the European Research Area Specific Programme", Contract Number RII3-CT-2004-506008 for support of the work of data collection at the EMBL X11 beamline at the DORIS storage ring, DESY, Hamburg (Project no.: PX-07-91). 
Table 1. Crystal data and structure refinement for the thymol $/ \beta-\mathrm{CD}$, carvacrol $/ \beta \mathrm{CD}$ and eugenol $/ \beta \mathrm{CD}$ complexes

\begin{tabular}{|c|c|c|c|}
\hline & Thymol/ $\beta$-CD & Carvacrol $/ \beta$-CD & Eugenol $/ \beta$-CD \\
\hline Chemical formula & $\begin{array}{l}\left(\mathrm{C}_{42} \mathrm{H}_{70} \mathrm{O}_{35}\right)_{2}\left(\mathrm{C}_{10} \mathrm{H}_{14} \mathrm{O}\right)_{2} \\
\left(\mathrm{H}_{2} \mathrm{O}\right)_{16}\end{array}$ & $\begin{array}{l}\left(\mathrm{C}_{42} \mathrm{H}_{70} \mathrm{O}_{35}\right)\left(\mathrm{C}_{10} \mathrm{H}_{14} \mathrm{O}\right)_{0 .} \\
{ }_{5}\left(\mathrm{H}_{2} \mathrm{O}\right)_{8}\end{array}$ & $\begin{array}{l}\left(\mathrm{C}_{42} \mathrm{H}_{70} \mathrm{O}_{35}\right)\left(\mathrm{C}_{10} \mathrm{H}_{12} \mathrm{O}_{2}\right)_{1} \\
{ }_{5}\left(\mathrm{H}_{2} 0\right)_{12.5}\end{array}$ \\
\hline$M_{\mathrm{r}}$ & 2721.15 & 1299.46 & 1556.01 \\
\hline $\begin{array}{l}\text { Crystal system, space } \\
\text { group }\end{array}$ & Triclinic, $P 1$ & Monoclinic, $C 2$ & Monoclinic, $C 2$ \\
\hline Temperature (K) & 100 & 293 & 100 \\
\hline$a, b, c(\AA)$ & $\begin{array}{l}15.289(15), 15.443 \\
(15), 15.549(16)\end{array}$ & $\begin{array}{l}19.300(19), 24.588 \\
(2), 15.844(3)\end{array}$ & $\begin{array}{l}19.589(5), 24.203(3), \\
16.378(19)\end{array}$ \\
\hline$\alpha, \beta, \gamma\left(^{\circ}\right)$ & $\begin{array}{l}104.432(5), 101.076 \\
(5), 104.036(5)\end{array}$ & $90,109.491(5), 90$ & 90, 103.484 (19), 90 \\
\hline$V\left(\AA^{3}\right) / Z$ & $3322(6) / 1$ & $7088(7) / 4$ & $7551(9) / 4$ \\
\hline Radiation type & $\begin{array}{l}\text { Synchrotron, } \lambda= \\
0.81560 \AA\end{array}$ & $\begin{array}{l}\text { Synchrotron, } \lambda= \\
0.80750 \AA\end{array}$ & $\begin{array}{l}\text { Synchrotron, } \lambda= \\
0.80510 \AA\end{array}$ \\
\hline Crystal size (mm) & $0.80 \times 0.40 \times 0.40$ & $0.6 \times 0.4 \times 0.4$ & $0.8 \times 0.8 \times 0.4$ \\
\hline$\theta$-range collection $\left(^{\circ}\right)$ & $1.91-29.42$ & $2.44-30.31$ & $1.91-28.63$ \\
\hline Index range & $\begin{array}{l}0 \leq \mathrm{h} \leq 18,-18 \leq \mathrm{k} \leq 18,- \\
18 \leq 1 \leq 18\end{array}$ & $\begin{array}{l}-24 \leq \mathrm{h} \leq 24,-30 \leq \mathrm{k} \leq \\
23,-19 \leq 1 \leq 10\end{array}$ & $\begin{array}{l}0 \leq \mathrm{h} \leq 23,0 \leq \mathrm{k} \leq 28, \\
19 \leq 1 \leq 18\end{array}$ \\
\hline Reflections collected & 38100 & 29916 & 16809 \\
\hline $\begin{array}{l}\text { Independent and } \\
\text { observed }[I>2 \sigma(I)] \\
\text { reflections }\end{array}$ & $10577 / 10534$ & $7267 / 6,837$ & $6503 / 6410$ \\
\hline$R_{\text {int }}$ & 0.038 & 0.051 & 0.065 \\
\hline Goodness-of-fit & 1.038 & 1.070 & 1.025 \\
\hline$R\left[F^{2}>2 \sigma\left(F^{2}\right)\right], w R\left(F^{2}\right)$ & $0.091,0.283$ & $0.086,0.258$ & $0.088,0.253$ \\
\hline $\begin{array}{l}\text { No. of parameters / } \\
\text { restraints }\end{array}$ & $1442 / 3$ & $744 / 22$ & $893 / 3$ \\
\hline $\begin{array}{l}\text { Largest difference peak } \\
\text { and hole }\left(\mathrm{e} \AA^{-3}\right)\end{array}$ & $0.31,-0.32$ & $0.06,-0.05$ & $0.71,-0.51$ \\
\hline
\end{tabular}


Table 2. Hydrogen bonds formed between the $-\mathrm{OH}$ of the thymol encapsulated inside the host molecules. The measured distances and angles meet the criteria for the formation of linear $\mathrm{CH}$... O bonds [24*]

\begin{tabular}{|c|c|c|}
\hline & Distance $(\AA)$ & Angle $\left(^{\circ}\right)$ \\
\hline \multicolumn{3}{|l|}{ G(A1) ... Host(A) } \\
\hline $\mathrm{C} 1-\mathrm{OH} \ldots \mathrm{O} 42 \mathrm{~A}$ & $2.903(2)$ & $128.66(5)$ \\
\hline $\mathrm{O} \ldots \mathrm{H} 53 \mathrm{~A}-\mathrm{C} 53 \mathrm{~A}$ & $2.398(2)$ & $162.14(2)$ \\
\hline $\mathrm{O} \ldots \mathrm{H} 52 \mathrm{~A}-\mathrm{C} 52 \mathrm{~A}$ & $2.479(2)$ & $140.43(3)$ \\
\hline \multicolumn{3}{|l|}{ G(A2) ... Host(A) } \\
\hline $\mathrm{C} 1-\mathrm{OH} \ldots \mathrm{O} 43 \mathrm{~A}$ & $2.737(3)$ & $131.28(5)$ \\
\hline $\mathrm{O} \ldots \mathrm{H} 53 \mathrm{~A}-\mathrm{C} 53 \mathrm{~A}$ & $2.540(2)$ & $133.54(5)$ \\
\hline $\mathrm{O} \ldots \mathrm{H} 54 \mathrm{~A}-\mathrm{C} 54 \mathrm{~A}$ & $2.524(2)$ & $158.78(2)$ \\
\hline \multicolumn{3}{|l|}{ G(A3) ... Host(A) } \\
\hline $\mathrm{C} 1-\mathrm{OH} \ldots \mathrm{O} 46 \mathrm{~A}$ & $2.825(3)$ & $129.70(4)$ \\
\hline O ... H56A - C56A & $2.596(2)$ & $136.53(1)$ \\
\hline O ... H57A - C57A & $2.641(2)$ & $152.37(3)$ \\
\hline \multicolumn{3}{|l|}{ G(B1) ... Host(B) } \\
\hline $\mathrm{C} 1-\mathrm{OH} \ldots \mathrm{O} 44 \mathrm{~B}$ & $2.825(7)$ & $121.82(12)$ \\
\hline O ... H54B - C54B & $2.776(3)$ & $130.2(5)$ \\
\hline $\mathrm{O} \ldots \mathrm{H} 55 \mathrm{~B}-\mathrm{C} 55 \mathrm{~B}$ & $2.482(2)$ & $153.0(5)$ \\
\hline G(B2) ... Host(B) & & \\
\hline $\mathrm{C} 1-\mathrm{OH} \ldots \mathrm{O} 45 \mathrm{~B}$ & $2.835(7)$ & $129.79(13)$ \\
\hline O ... H55B - C55B & $2.561(2)$ & $138.5(5)$ \\
\hline $\mathrm{O} \ldots \mathrm{H} 56 \mathrm{~B}-\mathrm{C} 56 \mathrm{~B}$ & $2.760(2)$ & $147.5(7)$ \\
\hline
\end{tabular}


Table 3. Indicative geometrical features of the observed $\mathrm{CH} / \pi$ interactions in the Thymol/ $\beta$-CD complex

\begin{tabular}{|c|c|c|c|c|c|}
\hline $\mathrm{C}-\mathrm{H}$ & $\begin{array}{l}\pi \text {-system } \\
\text { (phenyl ring) }\end{array}$ & $\theta\left({ }^{\circ}\right)$ & $D_{\mathrm{atm}}(\AA)$ & $D_{\mathrm{pln}}(\AA)$ & Region \\
\hline Host(A) & $\mathrm{G}(\mathrm{A} 1)-\left[\mathrm{C}^{1}\right]$ & & & & \\
\hline C31A-H31A & C5(A1) & $18.30(2)$ & $3.063(2)$ & $3.027(3)$ & 1 \\
\hline C35A-H35A & $\mathrm{C} 5(\mathrm{~A} 2)$ & $14.14(2)$ & $3.093(3)$ & $3.030(3)$ & 1 \\
\hline C31A-H31A & C5(A3) & $15.12(2)$ & $2.949(2)$ & $2.948(2)$ & 1 \\
\hline $\operatorname{Host}(\mathrm{B})$ & $\mathrm{G}(\mathrm{B} 1)-\left[\mathrm{C}^{1}\right]$ & & & \\
\hline \multirow[t]{2}{*}{ C34B-H34B } & C6(B1) & $12.792(4)$ & $2.694(2)$ & $\omega=128.4(4)^{\circ}$ & \\
\hline & & & & \multicolumn{2}{|l|}{$\mathrm{D}_{\text {lin }}=2.650(3) \AA$} \\
\hline C33B-H33B & $\mathrm{C} 4(\mathrm{~B} 1)$ & $4.3(4)$ & $3.092(3)$ & $3.058(3)$ & 1 \\
\hline C37B-H37B & $\mathrm{C} 5(\mathrm{~B} 2)$ & 21.1(4) & $3.198(2)$ & $3.169(3)$ & $\begin{array}{c}\text { Close } \\
\text { to } 1\end{array}$ \\
\hline $\mathrm{G}(\mathrm{A} 1)$ & $\mathrm{G}(\mathrm{B} 1)-\left[\mathrm{C}^{1}\right]$ & & & & \\
\hline $\mathrm{C}(\mathrm{A} 1)-\mathrm{H}(\mathrm{A} 1) 1$ & C6(B1) & $20.967(12)$ & $2.956(3)$ & $2.722(3)$ & 1 \\
\hline $\mathrm{C}(\mathrm{B} 1)-\mathrm{H}(\mathrm{B} 1) 1$ & $\mathrm{C} 4(\mathrm{~A} 1)$ & 28.3(7) & $2.761(2)$ & $2.706(2)$ & 1 \\
\hline $\mathrm{C}(\mathrm{B} 1)-\mathrm{H}(\mathrm{B} 1) 1$ & C6(A3) & $23.0(7)$ & $2.689(2)$ & $2.675(2)$ & 1 \\
\hline $\mathrm{C}(\mathrm{B} 2)-\mathrm{H}(\mathrm{B} 2) 1$ & C6(A2) & $33.75(2)$ & $3.044(3)$ & $3.005(3)$ & 1 \\
\hline
\end{tabular}

$\mathrm{C}^{1}$ and $\mathrm{C}^{2}$ : nearest and second nearest $\mathrm{sp}^{2}$-carbons, respectively, to $\mathrm{H} ; D_{\text {atm: }}$ : interatomic distance $\left(\mathrm{H} / \mathrm{C}^{1}\right) ; D_{\mathrm{pln}}$ : $\mathrm{H} / \pi$-plane distance; $\mathrm{D}_{\text {lin }}$ : distance between $\mathrm{H}$ and line $\mathrm{C}^{1} \mathrm{C}^{2} ; \theta$. angle of $\mathrm{HCC}^{1} ; \omega$ : dihedral angle between guest's phenyl and $\mathrm{HC}^{1} \mathrm{C}^{2}$ planes. 


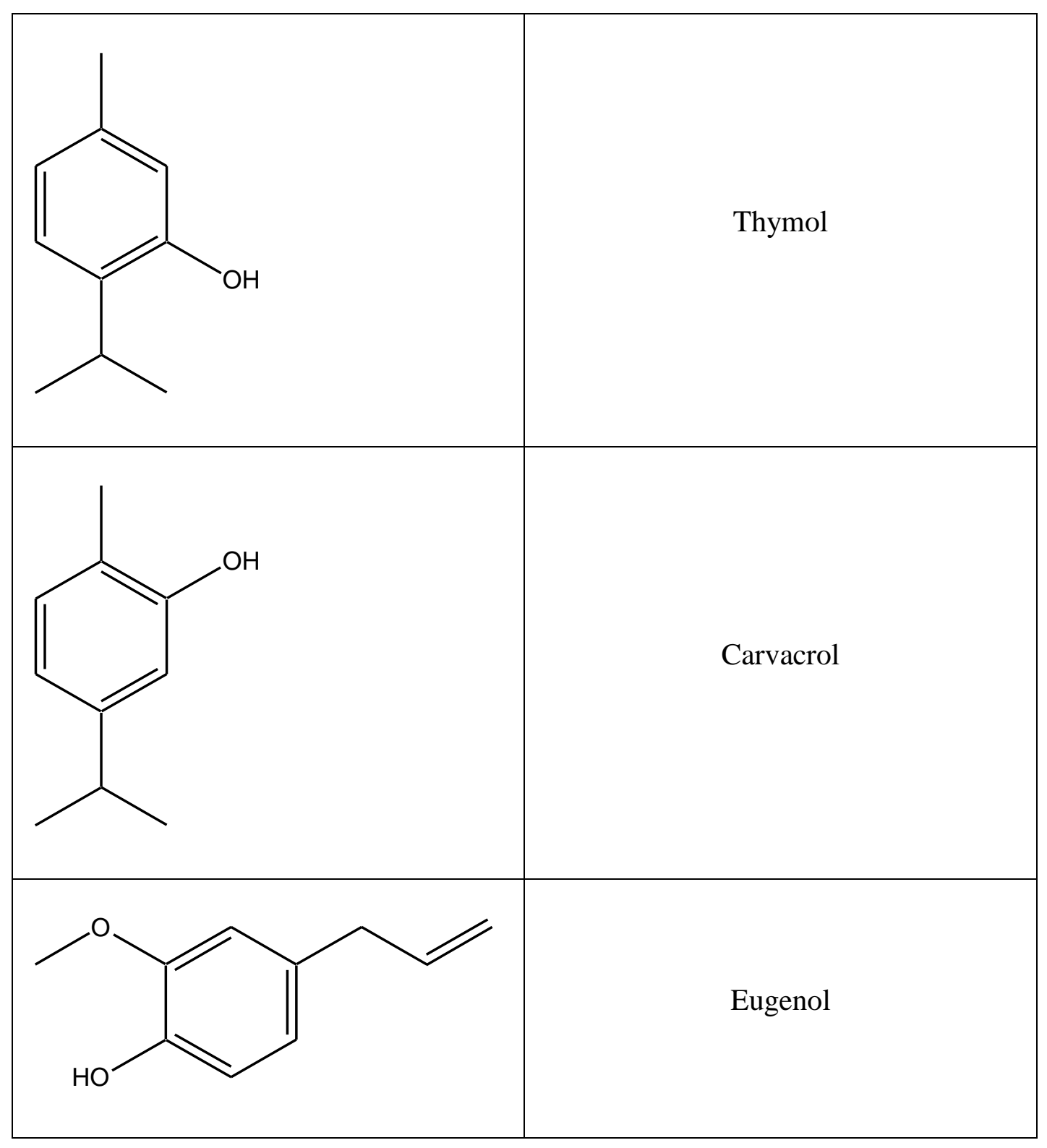

Scheme 1 


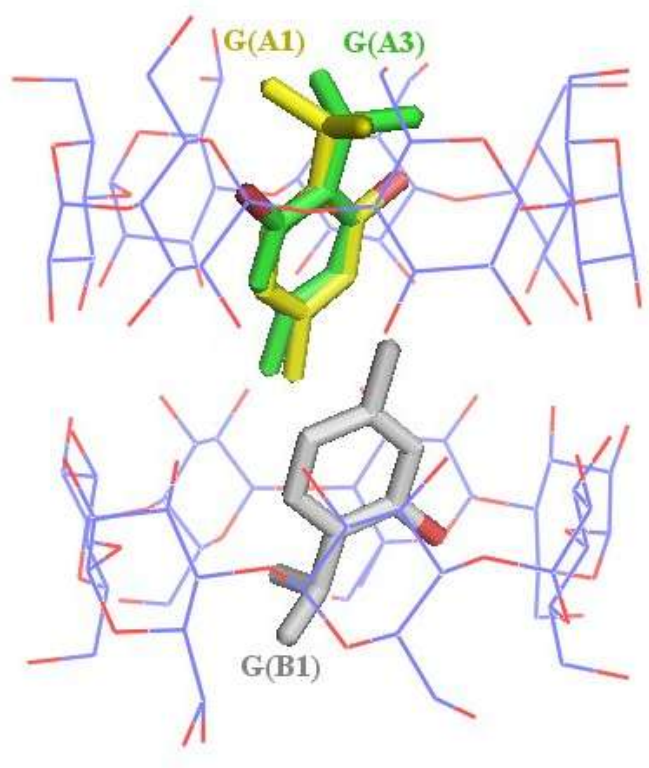

(a)

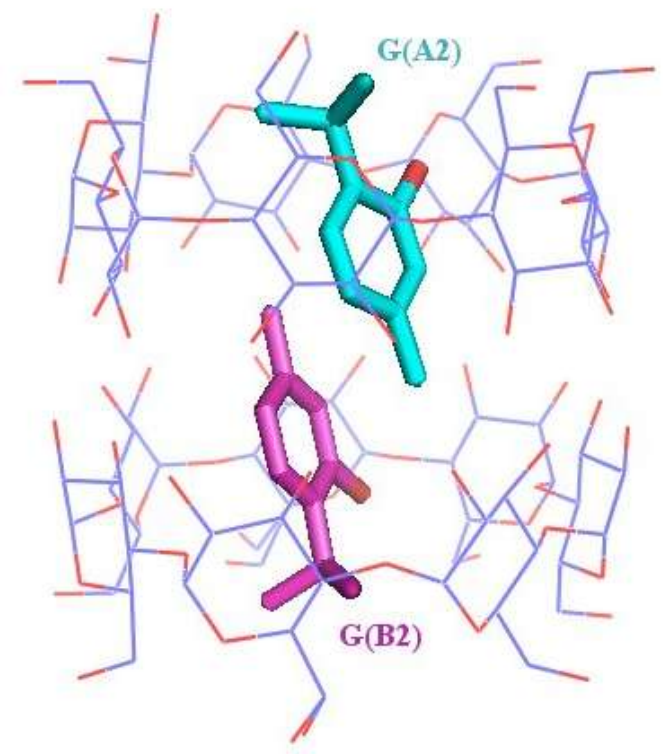

(b)

Figure 1 The thymol/ $\beta$-CD $2 / 2$ dimeric inclusion complex. The guest molecules $\mathrm{G}(\mathrm{A})$ and $\mathrm{G}(\mathrm{B})$ occupy the sites: (a) $\mathrm{G}(\mathrm{A} 1)-\mathrm{G}(\mathrm{B} 1)$ with occupancy 0.45 or $\mathrm{G}(\mathrm{A} 3)-\mathrm{G}(\mathrm{B} 1)$ with occupancy 0.25 or (b) G(A2) - G(B2) with occupancy 0.30

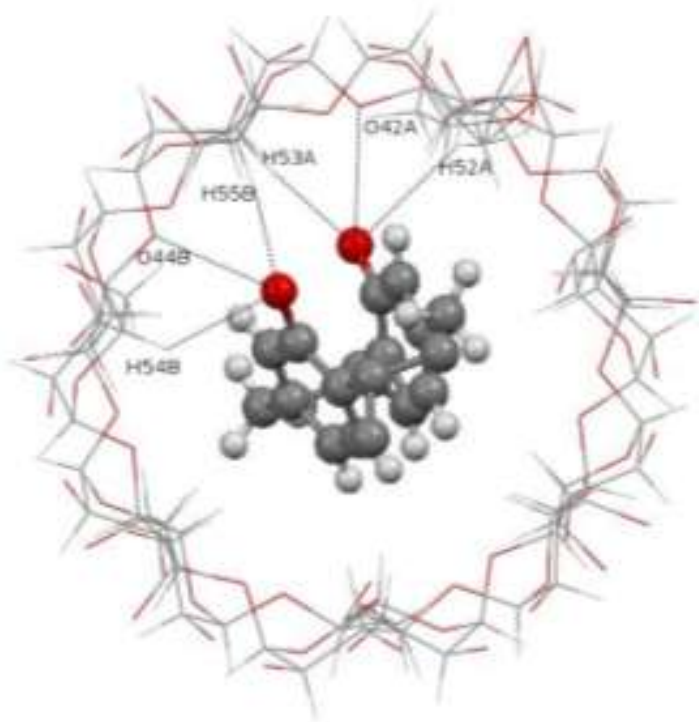

(a)



(b)

\section{Figure 2}

(a) - $\mathrm{OH}$ group of the encapsulated thymol forming a H-bond with the O4(i) of the host and two $\mathrm{CH}$... O bonds with the H5(i) and H5(i+1) of the Dglucopyranoside units bridged at the O4(i) by the $(1,4)$ glucoside bond. (b) Mutual 
$\mathrm{CH} / \pi$ interactions between the thymol guest molecules. For clarity only the occupied sites $\mathrm{G}(\mathrm{A} 1)$ and $\mathrm{G}(\mathrm{B} 1)$ are drawn, no water molecules and in (b) only the $\mathrm{H}$-atoms of the $-\mathrm{CH}_{3}$ group of the guests.

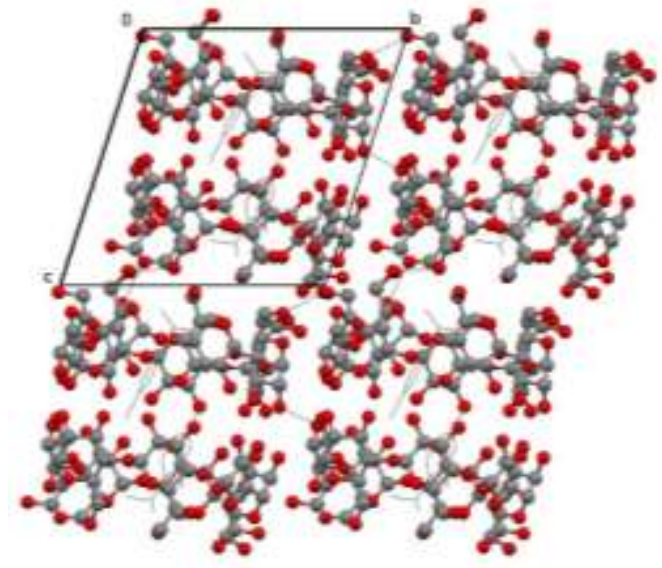

(a)

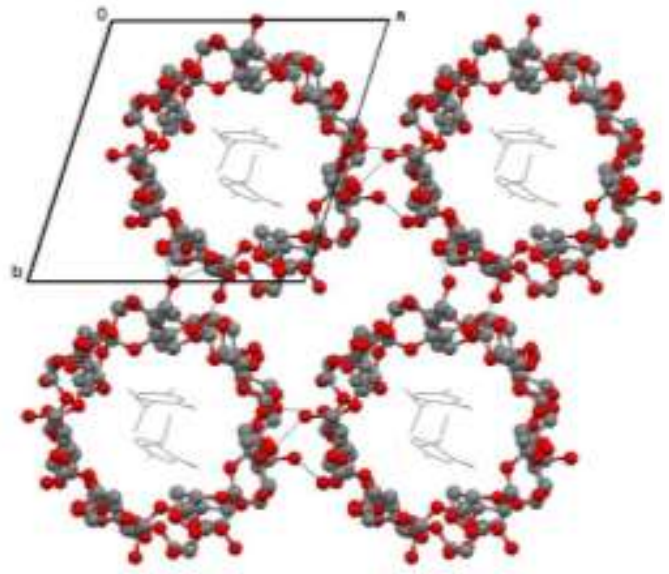

(b)

Figure 3 The molecular packing of the Thymol $/ \beta$-CD. Channels formed along the $c$ axis. Views of the (a) bc plane (b) ab plane

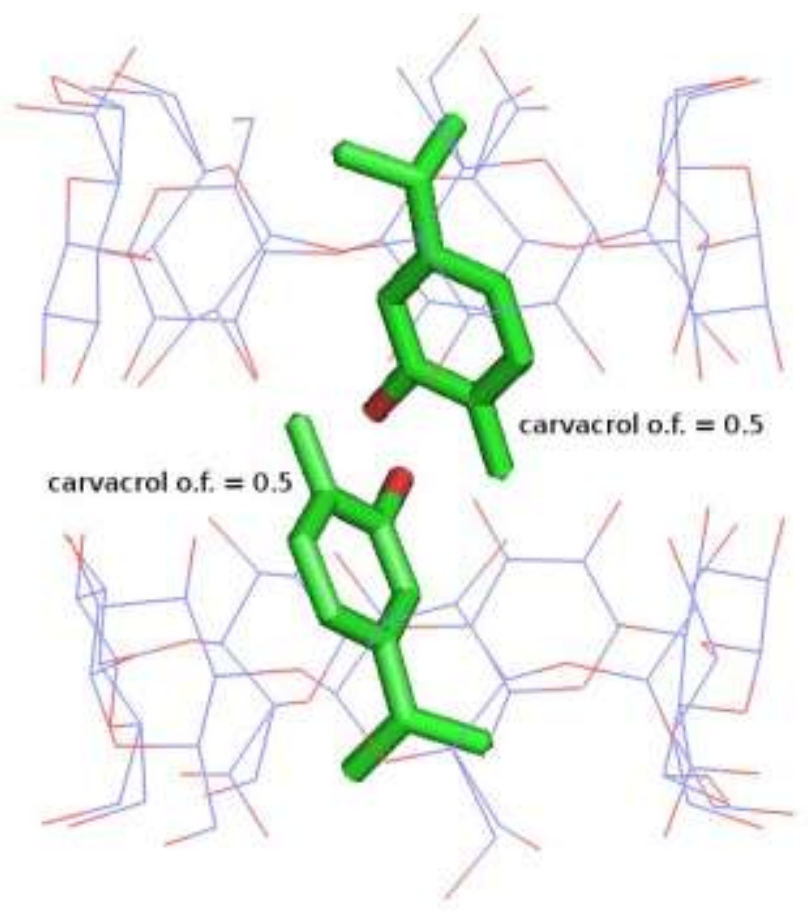

Figure 4. The formed dimer of the carvacrol/ $\beta$-CD complex. The occupancy factor (o.f) of the carvacrol molecule encapsulated within each $\beta$-CD cavity is 0.5 , therefore, only one guest molecule is accommodated inside the dimeric cavity the guest/host stoichiometry being $1 / 2$. 


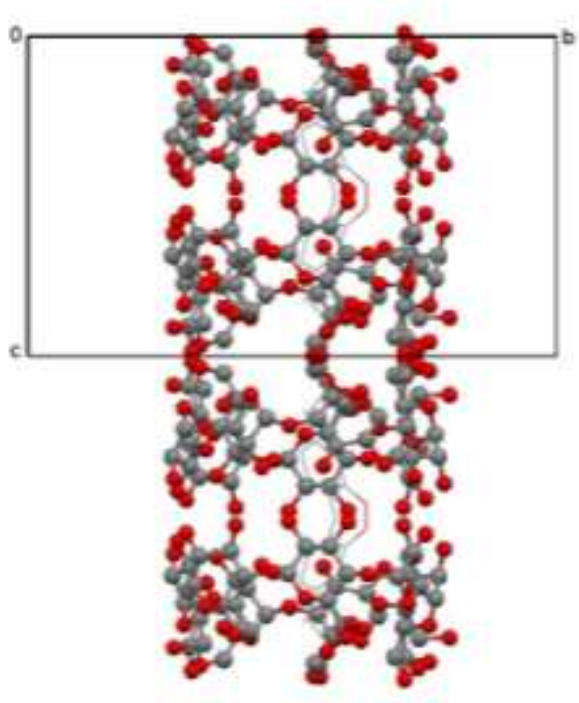

(a)



(b)

Figure 5 The molecular packing of the Carvacrol $/ \beta$-CD. Channels formed along the $c$ axis. Views of the (a) bc plane (b) ab plane

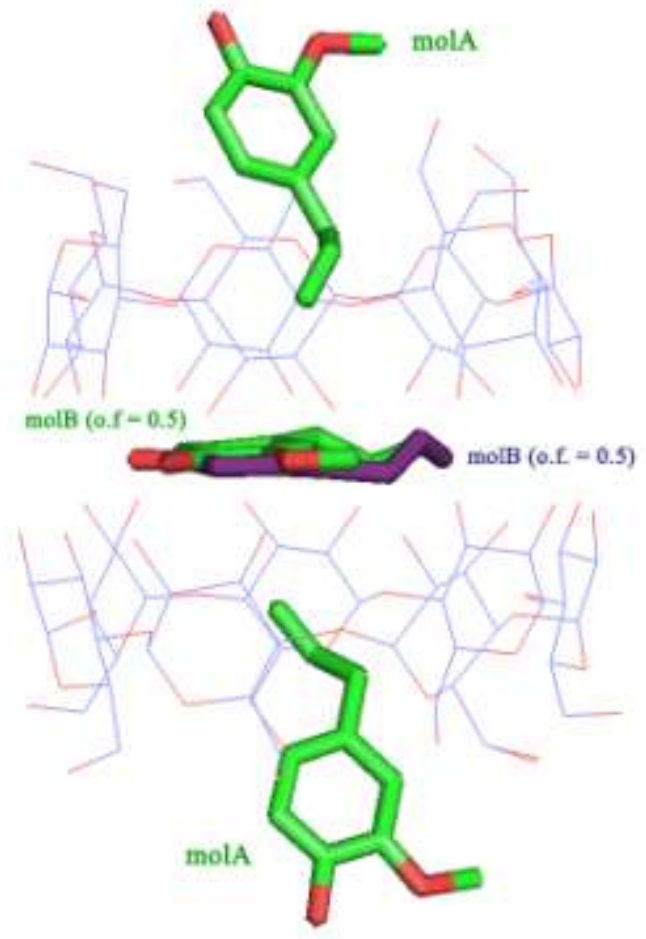

Figure 6 The eugenol $/ \beta$-CD 3/2 dimeric inclusion complex. The occupancy factor (o.f) of the molA and molB is 1 and 0.5 respectively. 


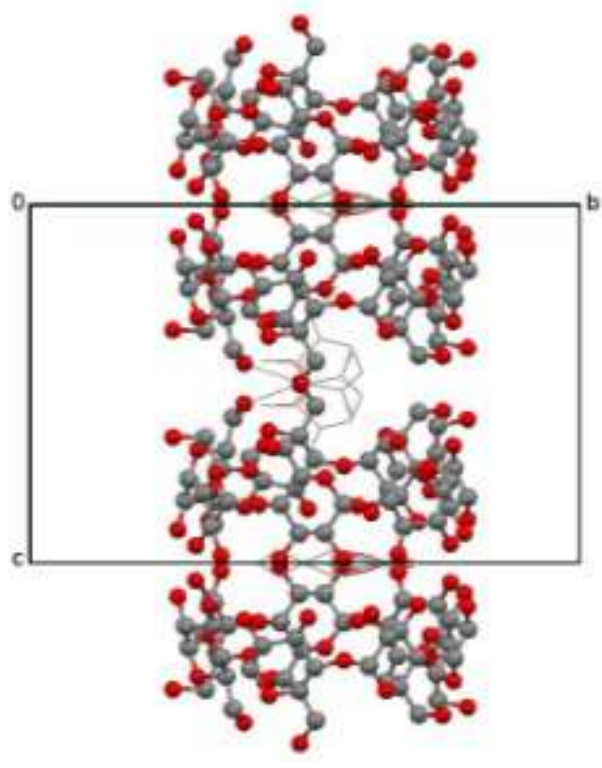

(a)

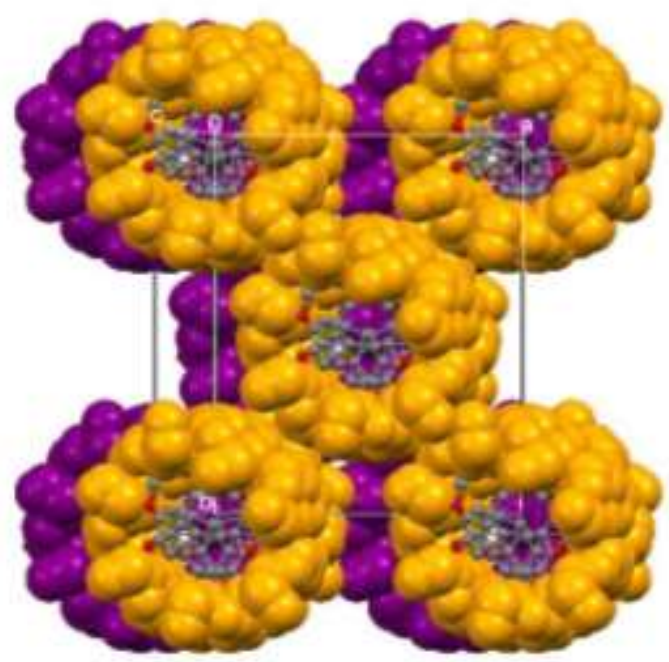

(b)

Figure 7 The molecular packing of the Eugenol/ $\beta$-CD follows the Tetrad mode (TT). View (a) of the bc plane (b) perpendicular to the $c^{*}$ axis.

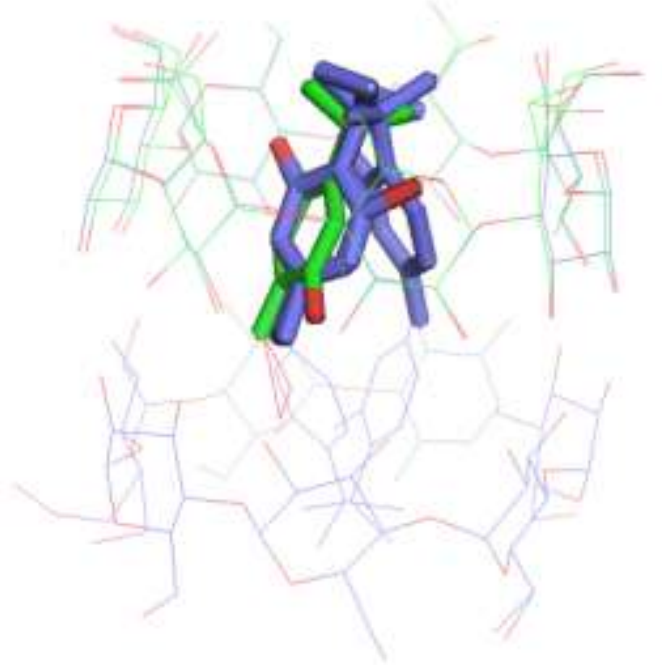

Figure 8 Alignment of the thymol/ $\beta-\mathrm{CD}$ (violet color) and the carvacrol $/ \beta-\mathrm{CD}$ (green color) complexes. In both cases the guest molecules are encapsulated inside the hydrophobic cavity with the same inclination and at the same immersion depth.

\section{References}

1 Cimanga K, Kambu K, Tona L, Apers S, De Bruyne T, Hermans N, Totte $\mathrm{J}$, Pieters L , and Vlietinck AJ. Correlation between chemical composition and 
antibacterial activity of essential oils of some aromatic medicinal plants growing in the democratic republic of congo. J Ethnopharmacol. 2002; 79: 213-20

2 Didry N, Dubreuil L , and Pinkas M. [antibacterial activity of thymol, carvacrol and cinnamaldehyde alone or in combination]. Pharmazie. 1993; 48:

301-4

3 Vazquez BI, Fente C, Franco CM, Vazquez MJ ,and Cepeda A. Inhibitory effects of eugenol and thymol on penicillium citrinum strains in culture media and cheese. Int J Food Microbiol. 2001; 67: 157-63

$4 \quad$ Venturini ME, Blanco D , and Oria R. In vitro antifungal activity of several antimicrobial compounds against penicillium expansum. Journal of Food Protection. 2002; 65: 834-39

5 Shimoda K, Kondo Y, Nishida T, Hamada H , and Nakajima N. Biotransformation of thymol, carvacrol, and eugenol by cultured cells of eucalyptus perriniana. Phytochemistry. 2006; 67: 2256-61

6 Del Valle EMM. Cyclodextrins and their uses: A review. Process Biochemistry. 2004; 39: 1033-46

7 Saenger W. Cyclodextrin inclusion compounds in research and industry. Angewandte Chemie International Edition in English. 1980; 19: 344-62

8 Mulinacci N, Melani F, Vincieri FF, Mazzi G , and Romani A. H-1-nmr noe and molecular modelling to characterize thymol and carvacrol betacyclodextrin complexes. International Journal of Pharmaceutics. 1996; 128: 81-88 9 Locci E, Lai SM, Piras A, Marongiu B , and Lai A. C-13-cpmas and h-1nmr study of the inclusion complexes of beta-cyclodextrin with carvacrol, thymol, and eugenol prepared in supercritical carbon dioxide. Chemistry \& Biodiversity. 2004; 1: 1354-66

10 Divakar S , and Maheswaran MM. Structural studies on inclusion compounds of beta-cyclodextrin with some substituted phenols. Journal of Inclusion Phenomena and Molecular Recognition in Chemistry. 1997; 27: 113-26 11 Fernandes LP, Ehen Z, Moura TF, Novak C , and Sztatisz J.

Characterization of lippia sidoides oil extract-beta-cyclodextrin complexes using combined thermoanalytical techniques. Journal of Thermal Analysis and Calorimetry. 2004; 78: 557-73

12 Yang Y , and Song LX. Study on the inclusion compounds of eugenol with alpha-, beta-, gamma- and heptakis (2,6-di-o-methyl)-beta-cyclodextrins. Journal of Inclusion Phenomena and Macrocyclic Chemistry. 2005; 53: 27-33

13 Nuchuchua O, Samoo S, Sramala I, Puttipipatkhachorn S, Soottitantawat A , and Ruktanonchai U. Physicochemical investigation and molecular modeling of cyclodextrin complexation mechanism with eugenol. Food Research International. 2009; 42: 1178-85

14 Fan Z, Guo MJ, Dong B, Jing ZL, Chen X, and Diao CH. Structure of the beta-cyclodextrin-thymol supramolecular complex in the solid state and in solution. Acta Chimica Sinica. 2010; 68: 798-802

15 Daferera DJ, Tarantilis PA, and Polissiou MG. Characterization of essential oils from lamiaceae species by fourier transform raman spectroscopy. $\mathrm{J}$ Agric Food Chem. 2002; 50: 5503-7

16 Otwinowski Z and Minor W. [20] processing of x-ray diffraction data collected in oscillation mode. In: Charles W. Carter, Jr., editor. Methods in enzymology,ed. Academic Press; 1997. pp. 307-26.

17 Bethanis K, Tzamalis P, Hountas A, Tsoucaris G, Kokkinou A , and Mentzafos D. New developments of the twin algorithm for phase extension and 
refinement in disordered supramolecular structures. Acta Crystallogr A. 2000; 56: 606-8

18 Beurskens PT, Beurskens G, de Gelder R, Garcia-Granda S, Gould RO ,and Smits JMM. The DIRDIF2008 program system. Crystallography Laboratory, University of Nijmegen, The Netherlands.

19 Rontoyianni A , and Mavridis IM. The crystal-structure of the inclusion complex of cyclomaltoheptaose (beta-cyclodextrin) with 3,5-dimethylbenzoic acid. Journal of Inclusion Phenomena and Molecular Recognition in Chemistry. 1994; 18: 211-27

20 Sheldrick GM. A short history of shelx. Acta Crystallographica Section A. 2008; 64: 112-22

21 Hubschle CB, Sheldrick GM , and Dittrich B. Shelxle: A qt graphical user interface for shelxl. J Appl Crystallogr. 2011; 44: 1281-84

22 Spek AL. Structure validation in chemical crystallography. Acta Crystallographica Section D. 2009; 65: 148-55

23 Dolomanov OV, Bourhis LJ, Gildea RJ, Howard JAK , and Puschmann H. Olex2: A complete structure solution, refinement and analysis program. Journal of Applied Crystallography. 2009; 42: 339-41

24 Steiner T. Unrolling the hydrogen bond properties of c-h center dot center dot center dot o interactions. Chemical Communications. 1997; 727-34

25 Takahashi H, Tsuboyama S, Umezawa Y, Honda K , and Nishio M. Ch/pi interactions as demonstrated in the crystal structure of host/guest compounds. A database study. Tetrahedron. 2000; 56: 6185-91

26 Mentzafos D, Mavridis IM, Lebas G , and Tsoucaris G. Structure of the 4tert-butylbenzyl alcohol beta-cyclodextrin complex - common features in the geometry of beta-cyclodextrin dimeric complexes. Acta Crystallographica Section B-Structural Science. 1991; 47: 746-57

27 Brett TJ, Alexander JM , and Stezowski JJ. Chemical insight from crystallographic disorder-structural studies of supramolecular photochemical systems. Part 2. The beta-cyclodextrin-4,7-dimethylcoumarin inclusion complex: A new beta-cyclodextrin dimer packing type, unanticipated photoproduct formation, and an examination of guest influence on beta-cd dimer packing. Journal of the Chemical Society-Perkin Transactions 2. 2000; 6: 1095-103 28 Tsorteki F, Bethanis K, Pinotsis N, Giastas P , and Mentzafos D. Inclusion compounds of plant growth regulators in cyclodextrins. V. 4-chlorophenoxyacetic acid encapsulated in beta-cyclodextrin and heptakis(2,3,6-tri-o-methyl)-betacyclodextrin. Acta Crystallographica Section B-Structural Science. 2005; 61: 207 17

29 Zhan H, Jiang ZT, Wang Y, Li R , and Dong TS. Molecular microcapsules and inclusion interactions of eugenol with beta-cyclodextrin and its derivatives. European Food Research and Technology. 2008; 227: 1507-13 